\title{
Structural integrity assurance of casing pipes in the oil and gas industry
}

\author{
M. Rakin ${ }^{1}$, M. Arsić ${ }^{2}$, B. Medjo ${ }^{1}$, Ž. Šarkoćević ${ }^{3}$ \& A. Sedmak ${ }^{4}$ \\ ${ }^{1}$ University of Belgrade, Faculty of Technology and Metallurgy, Serbia \\ ${ }^{2}$ Institute for Testing of Materials, Belgrade, Serbia \\ ${ }^{3}$ High Technical School of Professional Studies, Zvečan, Serbia \\ ${ }^{4}$ University of Belgrade, Faculty of Mechanical Engineering, Serbia
}

\begin{abstract}
The exploitation of casing steel pipes used in oil and gas drilling rigs typically involves a corrosive atmosphere, high pressures and elevated temperatures. These conditions can affect the initiation and development of defects in the material, which can jeopardize the safe service of the system. In this work, an assessment of the integrity of a damaged pipe, manufactured by high frequency contact welding (HF) of API J55 steel, is presented. The influence of an initial defect (machined surface crack) on the pipe structural integrity is analysed. Besides the defects at the internal surface, which is in contact with the transported fluid, casing pipes are also exposed to damage at the external surface, which is why such configuration is examined here. The analysed surface crack is in an axial direction, bearing in mind that this type of defect is the most severe for the cylindrical pressurised components.

Internal pressure testing is conducted on a pipe closed by dished ends. The values of fracture parameters, crack mouth opening displacement CMOD and $J$ integral, were tracked during the experiment. The applied procedure for $J$ integral determination (so-called direct measurement) can be applied both on standard specimens and on structures. It includes the use of combined experimental - computational procedure. Finite element analysis is used for determining the criteria for the pipe failure, regarding both crack growth initiation and plastic collapse of the ligament. The size of the crack is varied in the finite element models, in order to determine the influence of its size on the maximum loading. Simplified 2D models are also examined, with the aim of
\end{abstract}


determining the applicability of such approach. Based on the obtained results, criteria for the integrity assessment of the pipe are discussed.

Keywords: casing pipe safe service, fracture resistance, direct $J$ integral measurement, finite element method.

\section{Introduction}

The reliability of the oil and gas drilling rig systems is very important for continuous exploitation, but also for the environment protection. Pipeline specifications defined by the standard API 5CT mainly include the dimensions of the pipes and their joints, resistance of a pipe to the pressure at the inner or outer surface, mechanical properties and chemical composition. However, reasons that very often lead to the failures of the pipelines are insufficient crack initiation and propagation resistance.

Detected imperfections and defects, even if they have been classified as 'acceptable' during the control procedures, can sometimes develop to macroscopic cracks, which endanger the safe service of the structure. The influence of the cracks on the load carrying capacity is often estimated by fracture mechanics procedures, by taking the loading conditions, geometric factors (e.g. the size and position of a crack) and material properties into account. Many recent investigations (e.g. [1-8]) have dealt with the analysis of the pipes behaviour and failure, integrity assessment and remaining service life estimate. A significant amount of work has previously been done by the authors on examination of welded joints [9-11], which are often locations of initial defects on pipes and other structures, as well as on specimens cut from the pipeline base metal [12].

Determining the acceptable crack sizes and safety conditions is very important in structural integrity assessment of pipes, having in mind the requirements of structural safety and economical demands. In order to achieve a good assessment, an accurate estimate of the crack parameters is crucial; for elastic-plastic material behaviour it is the $J$ integral or crack tip opening displacement CTOD. These parameters enable a correlation between the level of damage (expressed through the crack size) and operating conditions, i.e. an application of the rule that fracture initiates when the applied crack driving force reaches a critical value.

In this paper, the aim is to estimate the influence of an axial surface crack on integrity of seam casing pipe made of API J55 steel. The load carrying capacity of the pipe is assessed by two different methods. The fracture resistance is determined by transferring the critical value of the $J$ integral from the compact tension (CT) specimens. Additionally, the plastic limit load (i.e. loading corresponding to the plastic collapse of the ligament) is assessed by elastic perfectly plastic numerical analysis. 


\section{Material properties and experimental testing of the pipe with a pre-crack}

Material properties are determined on specimens taken from the casing pipe manufactured by HF welding (producer US Steel, Serbia). The pipe was in exploitation in an oil drilling rig, and is withdrawn during a reparation procedure after about 70000 hours (8 years). This period is much shorter in comparison with the designed service life, which can be up to 30 years. Pressure test is conducted on axially pre-cracked pressure vessel made of a pipe segment, capped at both ends. Nominal dimensions of the pipe are: diameter $\phi 139.7 \mathrm{~mm}$, wall thickness $6.98 \mathrm{~mm}$.

Chemical composition of API J55 steel is given in Table 1. Yield strength and ultimate tensile strength are $380 \mathrm{MPa}$ and $562 \mathrm{MPa}$, respectively. More details on the specimens testing can be found in [13].

Table 1: $\quad$ Chemical composition of API J55 steel.

\begin{tabular}{|l|l|l|l|l|l|}
\hline $\mathrm{C}$ & $\mathrm{Si}$ & $\mathrm{Mn}$ & $\mathrm{P}$ & $\mathrm{S}$ & $\mathrm{Cr}$ \\
\hline 0.2924 & 0.233 & 0.963 & 0.013 & 0.0216 & 0.0995 \\
\hline $\mathrm{Ni}$ & $\mathrm{Mo}$ & $\mathrm{V}$ & $\mathrm{Cu}$ & $\mathrm{Al}$ & \\
\hline 0.0579 & 0.0123 & 0.003 & 0.131 & 0.025 & \\
\hline
\end{tabular}

In order to ensure a safe exploitation of the pipelines (which often contain some initial defects), a proper assessment of the crack initiation and growth in the casing pipes, used for the drilling rigs and subjected to high pressure, elevated temperature and chemically aggressive working environment, is essential. This can be achieved by proper quantification of the fracture mechanics parameters and other factors, which could lead to structure failure.

Experimental testing is conducted on a pressurized pipe with a machined axial external surface crack in the base material, figure 1 . The dimensions of the crack were: length $L=200 \mathrm{~mm}$, depth $a=3.5 \mathrm{~mm}$. The loading (internal pressure) was increased to the maximum value of 220 bar.
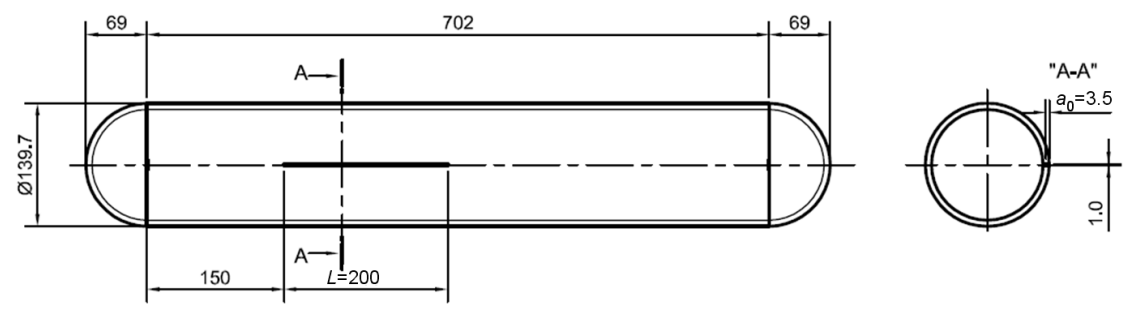

Figure 1: $\quad$ Pipe dimensions.

The strains in the vicinity of the pre-crack were determined by series of the strain gauges. The crack mouth opening displacement (CMOD) was measured using a COD gauge. 
Direct $J$ integral measurement [14], as a method for experimental determination of the $J$ integral value, is applied in this work. Unlike the standard evaluation procedure, direct measurement is based on the path independence of this fracture mechanics parameter. The results do not depend on the crack length; hence this method is more universal in comparison with the standard ones. However, it is more complicated and expensive, since it requires the use of the strain gauges and their chains for measuring strains at many locations, with short distances among them. The series of strain gauges in the vicinity of the crack tip and middle of the crack on the experimentally examined pipe are shown in figure 2 .

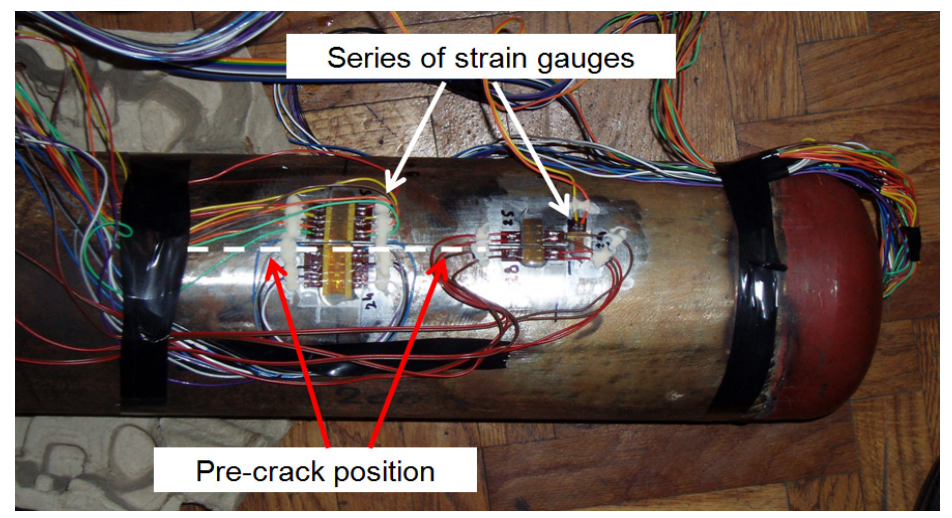

Figure 2: $\quad$ Photo of the pipe with a pre-crack, with strain gauges attached.

\section{Numerical analysis}

Numerical analysis of the stress and strain state of the examined pipe exposed to the internal pressure is performed by the finite element method (FEM), using the software package Abaqus (www.simulia.com). Three-dimensional model, consisting of 20-node elements, is shown in figure 3. Due to the symmetry of the geometry and loading, one quarter of the pipe is considered, with the geometry of the crack approximated by rectangular shape. Bearing in mind that the pipe was capped at both ends for experimental testing, appropriate axial loading is introduced at one end of the FE model in addition to the pressure loading on the internal surface. The value of $J$ integral during the increase of pressure is calculated using the domain integral (virtual crack extension) method [15]. The crack length in numerical analysis is varied, in order to determine the influence of this dimension on the load carrying capacity of the pipe exposed to internal pressure. 


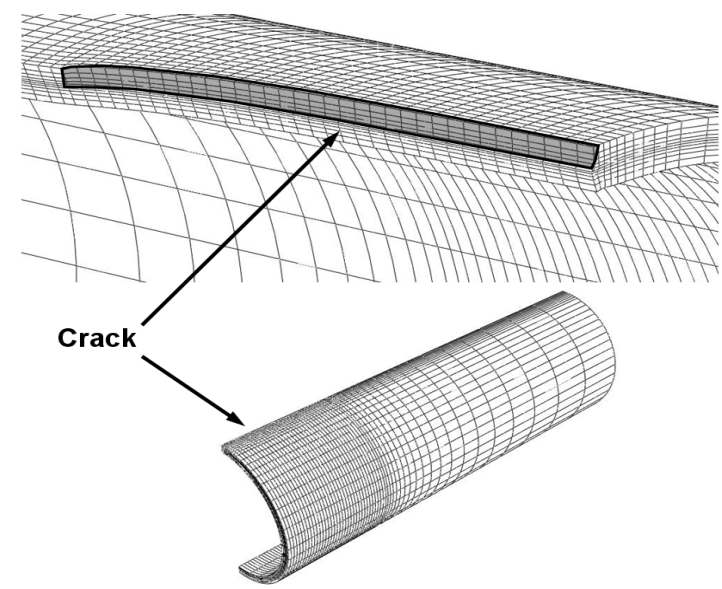

Figure 3: $\quad 3 \mathrm{D}$ FE mesh with enlarged part around the crack.

In addition to the model shown in figure 3, analysis is also conducted on a two-dimensional model, in order to assess the possibilities for this simplification. The finite element mesh is shown in figure 4; plane strain conditions are applied. Therefore, it can be said that this 2D model represents a pipe with infinitely long axial crack. The aim is to determine the crack length, which can be correctly represented by this simplified model.
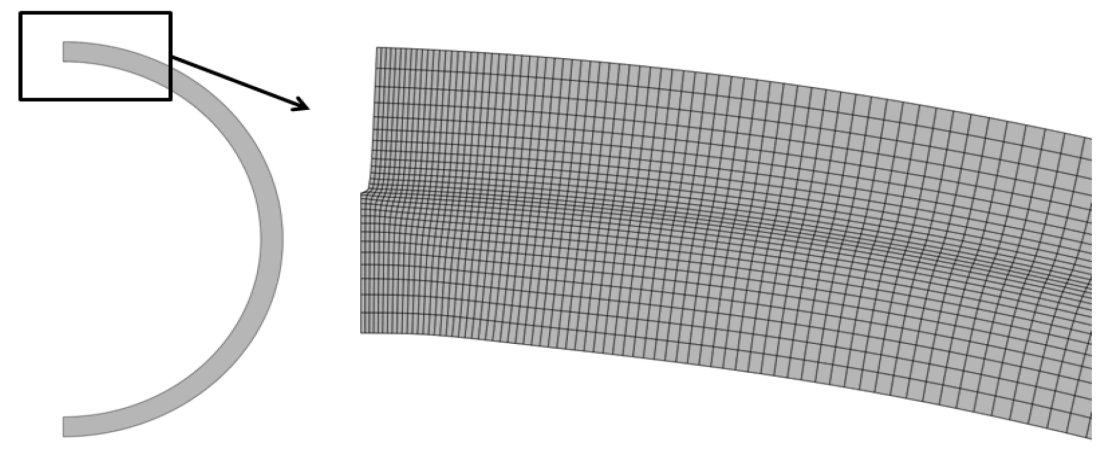

Figure 4: $\quad$ 2D FE mesh - deformed state.

\section{Results and discussion}

The CMOD values during the increase of loading obtained by FEM and experimentally are very similar, as shown in [6]. The results for $J$ integral are shown in figure 5, where certain difference can be seen. However, these 
differences become lower for higher pressure values, as the $J$ integral reaches its critical value $J_{I c}$. Such trend can be seen from the numerical, as well as extrapolated experimental results (figure 5).

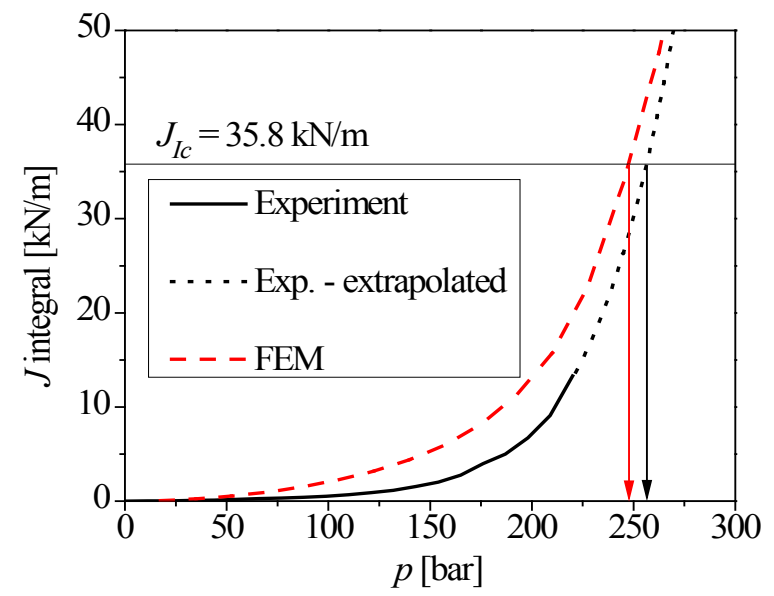

Figure 5: $\quad$ Comparison of the results for $J$ integral.

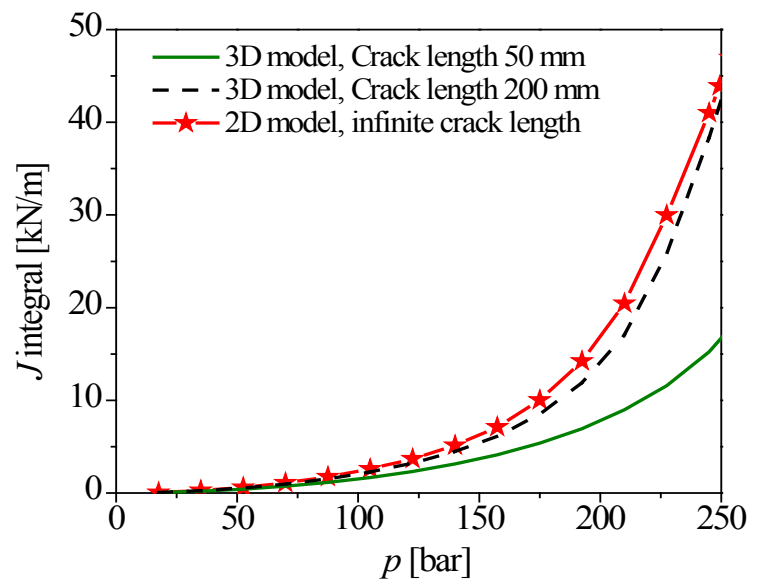

Figure 6: Comparison of the results for $J$ integral $-2 \mathrm{D}$ model and 3D models with different crack lengths.

The influence of the crack length on the $J$ integral values during the increase of loading is shown in figure 6. In addition to the model with crack length 200 $\mathrm{mm}$ (corresponding to the pre-crack on the experimentally examined pipe), a model with $50 \mathrm{~mm}$ long crack and 2D model are analysed. It can be seen that the $J$ integral increases much more slowly in the geometry with the shorter crack. On the other hand, the 3D model with $200 \mathrm{~mm}$ long crack exhibits similar results as the 2D model (having in mind the plane strain conditions, 2D model is 
equivalent to the model with infinitely long crack). This leads to the conclusion that two-dimensional simplification is justified for longer cracks, which will be further examined by comparing the failure conditions in the remainder of this section.

Based on the critical value of the $J$ integral, determined on CT specimens in [13], the pressure corresponding to crack initiation in the experimentally examined configuration is about 250 bar (figure 5). This loading value corresponds to one of the two applied failure criteria - reaching the critical value of fracture mechanics parameter.

However, it is well known that structures with initial defects can fail by either fracture or plastic collapse (development of the plasticity through the ligament), [16]. This failure mode is assessed by utilising the elastic - perfectly plastic material behaviour in the FE model [7, 17-19]. The problems related to convergence in such calculations are treated by application of the modified RIKS option in Abaqus. The plastic limit pressures are obtained from the RIKS factor (LPF - Load Proportionality Factor), which is the result of this FE analysis. When LPF value is known, the limit load (pressure) is determined by multiplying it with the pressure, which is defined as loading in the model.

The decrease of the load carrying capacity with the increase of the crack length is shown in Fig. 5. Maximum pressure values imply that the plastic limit load is attained after the fracture mechanics parameter has reached its critical value for all the crack lengths.

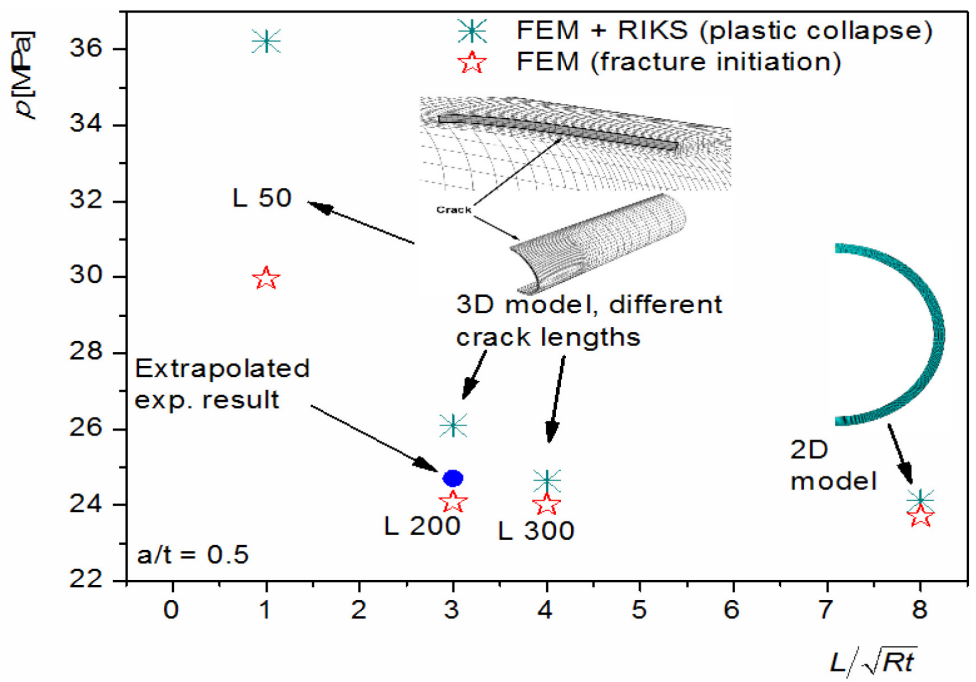

Figure 7: Dependence of maximum pressure on the crack length.

It can be seen that it is fully justified to use a simplified 2D model for longer axial cracks, because all maximum pressure values are approaching to the results of the plane strain model as the crack length increases. The advantage of the simplified model can be seen through computation time, which can be up to 100 
times shorter in comparison with the full 3D models analysed in this work. Another important notice is that the conservatism of the results is not endangered by the use of the $2 \mathrm{D}$ model, having in mind that the $2 \mathrm{D}$ results represent the minimum values.

It should also be noted that, besides the crack-like defects, corrosion damages occur very often on casing pipes in oil and gas drilling rigs and can cause pipe failure, which was considered in [8].

\section{Conclusions}

Failure of axially cracked pipes is analysed using fracture initiation and plastic collapse as failure criteria. The following can be concluded:

- The values of the $J$ integral are experimentally determined by direct measurement of the $J$ integral. Numerically determined values do not deviate significantly from the experimental ones, although certain differences exist. Extrapolation of experimental results is applied, due to the fact that the experimental test did not result in the pipe final failure.

- Dependence of the maximum pressure on the defect size (in this case: crack length) is established. In the finite element analysis, both crack initiation and plastic collapse are applied as failure criteria.

- $\quad$ For shorter cracks, crack initiation is predicted at lower loading level in comparison with the plastic collapse. For longer cracks, this difference is very small, i.e. both critical loads are similar.

- The possibility of application of simplified 2D models is examined, and the limits for the crack length in this case are determined. However, 2D results are always conservative and do not lead to prediction of higher load carrying capacity regardless of the crack length.

\section{Acknowledgement}

The authors gratefully acknowledge the support from the Serbian Ministry of Education, Science and Technological Development under the projects ON 174004 and TR 35002.

\section{References}

[1] Pati, P.K., Shrivastava, S.K. and Basu, S., Numerical analysis of crack initiation and growth in cylindrical geometries with an axial flaw. International Journal of Fracture, 148(4), pp. 291-301, 2007.

[2] Berg, E., Østby, E., Thaulow, C. and Skallerud, B., Ultimate fracture capacity of pressurised pipes with defects - Comparisons of large scale testing and numerical simulations. Engineering Fracture Mechanics, 75(8), pp. 2352-2366, 2008.

[3] Chattopadhyay, J., Dutta, B.K., Kushwaha, H.S., Roos, E. and Herter, K.H., Load bearing capacity of flawed piping components - comparison of 
experiment with calculation. International Journal of Pressure Vessels and Piping, 81(7), pp. 599-608, 2004.

[4] Gubeljak, N., Vojvodić Tuma, J., Šuštaršić, B., Predan, J. and Oblak, M., Assessment of the load-bearing capacity of a primary pipeline. Engineering Fracture Mechanics, 74(6), pp. 995-1005, 2007.

[5] Kozak, D., Ivandić, Z. and Konjatić, P., Determination of the critical pressure for a hot-water pipe with a corrosion defect. Materials and Technology. 44(6), pp. 385-390, 2010.

[6] Rakin, M., Arsić, M., Međo, B., Šarkoćević, Ž., Ivanović, I. and Sedmak, A., API J55 steel casing pipe with an initial surface crack under internal pressure - determination of fracture parameters. Key Engineering Materials, 488-489, pp. 577-580, 2012.

[7] Dimić, I., Arsić, M., Međo, B., Stefanović, A., Grabulov, V. and Rakin, M.: Effect of welded joint imperfection on the integrity of pipe elbows subjected to internal pressure. Technical Gazette, 20(2), pp. 285-291, 2013.

[8] Međo, B., Rakin, M., Arsić, M., Šarkoćević, Ž., Zrilić, M. and Putić, S.: Determination of the load carrying capacity of damaged pipes using local approach to fracture. Materials Transactions - JIM, 53(1), pp. 185-190, 2012.

[9] Younise, B., Rakin, M., Gubeljak, N., Međo, B., Burzić, M., Zrilić, M. and Sedmak, A, Micromechanical analysis of mechanical heterogeneity effect on the ductile tearing of weldments. Materials and Design, 37, pp. 193201, 2012.

[10] Younise, B., Rakin, M., Međo, B., Gubeljak, N., Kozak, D. and Sedmak, A.: Numerical analysis of constraint effect on ductile tearing in strength mismatched welded CCT specimens using micromechanical approach. Technical Gazette, 18(3), pp. 333-340, 2011.

[11] Manjgo, M., Međo, B., Milović, Lj., Burzić, Z., Rakin, M. and Sedmak, A.: Analysis of welded tensile plates with a surface notch in the weld metal and heat affected zone. Engineering Fracture Mechanics, 77(15), pp. 2958$2970,2010$.

[12] Međo, B., Rakin, M., Zrilić, M., Putić, S. and Sedmak, A.: Micromechanical estimate of critical values of $\mathrm{J}$ integral for steam pipeline steel. Materials Science, 45(4), pp. 523-531, 2009.

[13] Šarkoćević, Ž., Arsić, M., Međo, B., Kozak, D., Rakin, M., Burzić, Z., and Sedmak, A., Damage level estimate of API J55 steel for welded seam casing pipes. Strojarstvo: J Theory Appl Mech Eng, 51(4), pp. 303-311, 2009.

[14] Read, D.T., Experimental Method for Direct Evaluation of J-Contour Integral, ASTM STP 791, Philadelphia, Vol. II, pp. 199-208, 1983.

[15] Parks, D.M., The virtual crack extension method for nonlinear material behavior. Computer Methods in Applied Mechanics and Engineering, 12, pp. 353-364, 1977.

[16] FITNET: European Fitness-for-Service Network, http://www.eurofitnet.org 
[17] Kim, Y.J., Shim, D.J., Huh, N.S. and Kim, Y.J., Plastic limit pressures for cracked pipes using finite element limit analyses. International Journal of Pressure Vessels and Piping, 79(5), pp. 321-330, 2002.

[18] Huh, N.S., Kim, Y.J. and Kim, Y.J., Limit load solutions for pipes with through-wall crack under single and combined loading based on finite element analyses. Journal of Pressure Vessel Technology - Transactions of ASME, 129(3), pp. 468-473, 2007.

[19] Kim, Y.J., Shim, D.J., Nikbin, K., Kim, Y.J., Hwang, S.S. and Kim, J.S., Finite element based plastic limit loads for cylinders with part-through surface cracks under combined loading. International Journal of Pressure Vessels and Piping, 80(7,8), pp. 527-540, 2003. 